\title{
A Real-Life Multicenter National Study on Nintedanib in Severe Idiopathic Pulmonary Fibrosis
}

\author{
Sergio Harari ${ }^{a}$ Antonella Caminati ${ }^{a}$ Venerino Poletti ${ }^{b}$ Marco Confalonieri ${ }^{c}$ \\ Stefano Gasparini ${ }^{d}$ Donato Lacedonia ${ }^{e}$ Fabrizio Luppi ${ }^{f}$ Alberto Pescig ${ }^{9}$ \\ Alfredo Sebastiani $^{h}$ Paolo Spagnolo ${ }^{i}$ Carlo Vancheri ${ }^{j}$ Elisabetta Balestro ${ }^{i}$ \\ Martina Bonifazi $^{d}$ Stefania Cerri $^{f}$ Federica De Giacomi ${ }^{g}$ \\ Rossana Della Porta ${ }^{c}$ Maria Pia Foschino Barbaro ${ }^{e}$ Annalisa Fui ${ }^{k}$ \\ Patrizio Pasquinellih Roberta Rosso ${ }^{j}$ Sara Tomassetti ${ }^{b}$ Claudia Specchial, $m$ \\ Paola Rottolik for the ILDINET (Interstitial Lung Diseases Italian Network)
}

a U.O. di Pneumologia e Terapia Semi-Intensiva Respiratoria, Servizio di Fisiopatologia Respiratoria ed Emodinamica

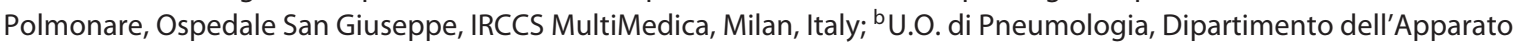
Respiratorio e del Torace, Ospedale G.P. Morgagni-L. Pierantoni, Forlì, Italy; ' ${ }^{\mathrm{D}}$ Department of Pulmonology, University

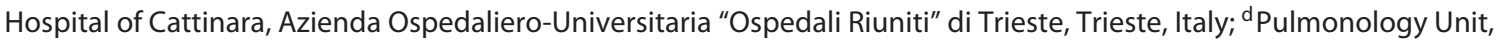
Department of Biomedical Sciences and Public Health, Università Politecnica delle Marche, Azienda OspedalieraUniversitaria "Ospedali Riuniti", Ancona, Italy; ' Department of Medical and Surgical Sciences, University of Foggia, Foggia, Italy; ${ }^{f}$ Center for Rare Lung Diseases, University Hospital Policlinico di Modena, Modena, Italy; ${ }^{9}$ Respiratory

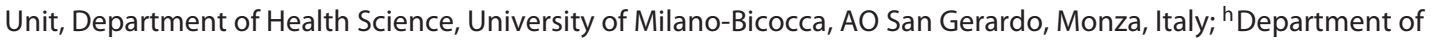
Respiratory Diseases, S. Camillo-Forlanini Hospital, Rome, Italy; ${ }^{i}$ Section of Respiratory Disease, Department of Cardiac, Thoracic, and Vascular Sciences, University of Padua, Padua, Italy; ${ }^{j}$ Regional Referral Centre for Rare Lung Disease, University of Catania, A.O.U. Policlinico-Vittorio Emanuele, Catania, Italy; ${ }^{\mathrm{k}}$ Respiratory Diseases and Lung Transplant Unit, Department of Internal and Specialist Medicine, AOUS, Siena, Italy; 'Department of Molecular and Translational

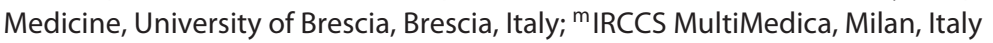

\section{Keywords}

Severe idiopathic pulmonary fibrosis - Therapy .

Nintedanib · Pirfenidone

\begin{abstract}
Background: Two therapeutic options are currently available for patients with mild-to-moderate idiopathic pulmonary fibrosis (IPF): pirfenidone and nintedanib. To date, there is still insufficient data on the efficacy of these 2 agents in patients with more severe disease. Objectives: This national,
\end{abstract}

multicenter, retrospective real-life study was intended to determine the impact of nintedanib on the treatment of patients with severe IPF. Methods: All patients included had severe IPF and had to have at least 6 months of follow-up before and at least 6 months of follow-up after starting nintedanib. The aim of the study was to compare the decline in lung function before and after treatment. Patient survival after 6 months of therapy with nintedanib was assessed. $\boldsymbol{R e}$ sults: Forty-one patients with a forced vital capacity (FVC) $\leq 50 \%$ and/or a diffusing capacity of the lung for carbon monoxide $\left(D_{L C O}\right) \leq 35 \%$ predicted at the start of nintedanib
KARGER

(c) 2018 S. Karger AG, Basel

E-Mail karger@karger.com

www.karger.com/res
Sergio Harari, MD

U.O. di Pneumologia e Terapia Semi-Intensiva Respiratoria

Ospedale San Giuseppe, IRCCS MultiMedica

via San Vittore 12, IT-20123 Milan (Italy)

E-Mail sharari@hotmail.it 
treatment were enrolled. At the 6-month follow-up, the decline of $D_{L C O}$ (both absolute and \% predicted) was significantly reduced compared to the pretreatment period (absolute $\mathrm{D}_{\mathrm{LCO}}$ at the -6-month, $\mathrm{T}_{0}$, and +6-month time points $(5.48,4.50$, and $5.03 \mathrm{mmol} / \mathrm{min} / \mathrm{kPa}$, respectively, $p=0.03$; $\mathrm{D}_{\mathrm{LCO}} \%$ predicted was $32.73,26.54$, and $29.23 \%$, respectively, $p=0.04)$. No significant beneficial effect was observed in the other functional parameters analyzed. The 1-year survival in this population was $79 \%$, calculated from month 6 of therapy with nintedanib. Conclusions: This nationwide multicenter experience in patients with severe IPF shows that nintedanib slows down the rate of decline of absolute and $\%$ predicted $D_{\text {LCO }}$ but does not have significant impact on FVC or other lung parameters.

(c) 2018 S. Karger AG, Basel

\section{Introduction}

For the treatment of idiopathic pulmonary fibrosis (IPF), an extremely disabling condition associated with a high mortality rate [1], 2 pharmaceutical agents, with mechanisms of action and pharmacological profiles very different from each other, have been on the market for some years now. Italian epidemiological data report a variable incidence and prevalence of IPF: between 2.3 and 5.3 cases per 100,000 person-years and between 12.6 and 35.5 cases per 100,000 person-years, respectively, depending on the criteria adopted for disease definition, with an average survival of 3.7 years from diagnosis [2].

The efficacy of the 2 agents in patients with mild-tomoderate IPF (as assessed by functional impairment) was proven by prospective multicenter randomized controlled studies [3-6] as well as in several real-life studies [7-12]. However, much less data are available on the efficacy of these new therapeutic options in patients with more advanced stages of the disease [13-15].

Nintedanib became available in Italy as well as in other European countries after the marketing of pirfenidone and following a compassionate use program (named patient use [NPU]). This program made the treatment available for subjects who were not eligible for pirfenidone therapy or who had suffered side effects from pirfenidone. Thus, the vast majority of patients admitted to the NPU program were affected by severe IPF, since only those with mild-to-moderate functional impairment were eligible for pirfenidone treatment. With this background, we collected data on such patients from all Italian reference centers for the diagnosis and treatment of IPF that had included at least 5 patients into the nintedanib
NPU program. The aim of the study was to assess the trend of lung function parameters in this subset of highly selected patients.

\section{Materials and Methods}

Study Design and Methods

In November 2014, Boehringer Ingelheim Inc. supported an NPU program that introduced nintedanib as a treatment for patients with IPF in Italy. In order to enter the study, patients had to be over 40 years of age and with a confirmed diagnosis of IPF in accordance with the international guidelines [1]. Subjects who were not eligible for the treatment with pirfenidone due to poor functional parameters (forced vital capacity $[\mathrm{FVC}] \leq 50 \%$ and/or diffusing capacity of the lung for carbon monoxide $\left[\mathrm{D}_{\mathrm{LCO}}\right] \leq 35 \%$ ) or those who had experienced intolerable side effects from the drug were included in the NPU program. Of the latter, only patients who met the severity functional criteria required by our study (FVC $\leq 50 \%$ predicted and/or $\mathrm{D}_{\mathrm{LCO}} \leq 35 \%$ predicted) were included in our series. Patients with an FVC $>50 \%$ could be also enrolled if they were unable to undergo $\mathrm{D}_{\mathrm{LCO}}$ testing, considering these patients with a severe disease. These patients had to have gone through a 6-month $(\mathrm{SD} \pm 2)$ follow-up period before starting nintedanib followed by a further follow-up period of at least 6 months $(\mathrm{SD} \pm 2)$ after starting treatment. A 6-month pretreatment period was believed to represent the minimum length of time to assess disease behavior in terms of lung function. Similarly, we considered 6 months to be the minimal period to evaluate response to the treatment.

Exclusion criteria for the NPU program included alanine aminotransferase, aspartate aminotransferase or bilirubin levels higher than 1.5 times the upper limit of normal; bleeding risk or thrombosis; planned major surgery within the next 3 months, including lung transplantation, major abdominal, or major intestinal surgery; myocardial infarction within the previous 6 months, or unstable angina within the last month. All patients were assessed for eligibility to the study through a centralized review supported by the sponsor. All patients gave their written informed consent, and approval by the ethics committee was obtained. The NPU program was closed in April 2016 when nintedanib became available on the Italian market for the treatment of IPF. We therefore asked all Italian reference centers for the diagnosis and treatment of IPF that had included at least 5 patients into the nintedanib NPU program to send us the files of the patients with a diagnosis of IPF established according to the 2011 international guidelines [1]. This was a spontaneous and unsponsored study. The coordinator center, San Giuseppe Hospital, Milan, obtained the authorization by its Ethics Committee (No. 285/2016). In compliance with the Italian regulations, the participating centers did or tried to acquire informed consent from the enrolled patients, since this was a retrospective trial. When informed consent was not possible to obtain due to death of the subject or his/her unavailability, track of the acquisition attempt was kept by the reference center.

The primary aim of the study was to evaluate the trend of lung function parameters before and after nintedanib treatment and to detect a possible change in the trend of the functional decline. Notably, we intended to assess whether the functional deterioration (in terms of \% predicted and/or absolute loss of FVC and $\mathrm{D}_{\mathrm{LCO}}$ ) 
could be modified by nintedanib. Survival of patients after the 6-month treatment period with nintedanib, which was determined through September 30, 2016, was also recorded.

\section{Statistical Analysis}

Lung function measurements were taken at 6 months (SD \pm 2 ) before starting treatment with nintedanib $\left(\mathrm{T}_{-1}\right)$, at the time of the first nintedanib intake $\left(\mathrm{T}_{0}\right)$, and at 6 months $(\mathrm{SD} \pm 2)$ after the start of nintedanib therapy $\left(\mathrm{T}_{1}\right)$. Changes in lung function parameters during the pretreatment $\left(\mathrm{T}_{0}-\mathrm{T}_{-1}\right)$ and posttreatment $\left(\mathrm{T}_{1}-\mathrm{T}_{0}\right)$ periods were then calculated.

The differences between post- and pretreatment modifications in lung function parameters were tested with the Wilcoxon signedrank test. In addition, the correlation between these differences was evaluated using the Spearman rank correlation coefficient.

All patients were followed up after $\mathrm{T}_{1}(6$ months after the initiation of nintedanib therapy). Vital status was determined by each participating center until September 30, 2016. The overall survival observed in the cohort was estimated using the Kaplan-Meier method. $p$ values $<0.05$ were considered statistically significant.

The statistical analysis was performed using STATA 11 (StataCorp 2009 Stata Statistical Software Release 11; StataCorp LP, College Station, TX, USA).

\section{Results}

Forty-one patients from 9 Italian centers were enrolled in the study. Table 1 shows the number of subjects included by each participating center. The mean age of the participants was 70 years $( \pm$ SD 8$)$ with a marked prevalence of males $(83 \%)$. The mean time from diagnosis was 20 months ( \pm SD 28 ). Only 7 subjects had been previously treated with pirfenidone, while the majority (59\%) had received low-dose steroids. Histological diagnosis was available only in 6 patients (15\%).

Figure 1 and Table 2 show the study results. The decline of both absolute $\mathrm{D}_{\mathrm{LCO}}$ and $\mathrm{D}_{\mathrm{LCO}} \%$ predicted was positively and significantly influenced by the introduction of nintedanib (absolute $\mathrm{D}_{\mathrm{LCO}}$ was $5.48 \mathrm{mmol} / \mathrm{min} /$ $\mathrm{kPa}$ at $\mathrm{T}_{-1}, 4.50$ at $\mathrm{T}_{0}$, and 5.03 at $\mathrm{T}_{1}, p=0.03 ; \mathrm{D}_{\mathrm{LCO}} \%$ predicted was $32.73 \%$ at $\mathrm{T}_{-1}, 26.4 \%$ at $\mathrm{T}_{0}$, and $29.23 \mathrm{~T}_{-1}, p=$ 0.04). No significant modifications were observed in the other parameters analyzed (FVC, forced expiratory volume in 1 second $\left[\mathrm{FEV}_{1}\right]$, total lung capacity [TLC], and $\left.\mathrm{FVC} \% / \mathrm{D}_{\mathrm{LCO}} \%\right)$. Since not all subjects were able to perform a 6-min walk test, the data available was insufficient to conduct a meaningful statistical analysis. Differences in changes between the post- and pretreatment values for $\mathrm{D}_{\mathrm{LCO}} \%$ and FVC\% were positively and significantly correlated ( $r h o=0.48, p=0.02$ ).

Two patients were excluded from the survival analysis because their follow-up data after the first 6 months of nintedanib treatment was unavailable. The median dura-

Nintedanib in Severe Idiopathic

Pulmonary Fibrosis
Table 1. Patient characteristics $(N=41)$ at baseline $\left(\mathrm{T}_{0}\right.$, first nintedanib intake)

\begin{tabular}{|c|c|}
\hline \multicolumn{2}{|l|}{ Center } \\
\hline Ancona & $3(7)$ \\
\hline Catania & $3(7)$ \\
\hline Foggia & $2(5)$ \\
\hline Forlì & $5(12)$ \\
\hline Milan & $7(17)$ \\
\hline Modena & $2(5)$ \\
\hline Monza & $4(10)$ \\
\hline Padua & $2(5)$ \\
\hline Rome & $5(12)$ \\
\hline Siena & $6(15)$ \\
\hline Trieste & $2(5)$ \\
\hline \multicolumn{2}{|l|}{ Gender } \\
\hline Female & $7(17)$ \\
\hline Male & $34(83)$ \\
\hline \multicolumn{2}{|l|}{$A g e^{\mathrm{a}}$} \\
\hline $55-64$ years & $7(17)$ \\
\hline $65-74$ years & $20(49)$ \\
\hline $75+$ years & $14(34)$ \\
\hline \multicolumn{2}{|l|}{ Smoking status } \\
\hline Ex-smoker & $28(68)$ \\
\hline Nonsmoker & $11(27)$ \\
\hline Smoker & $2(5)$ \\
\hline \multicolumn{2}{|c|}{ Histological diagnosis } \\
\hline No & $35(85)$ \\
\hline Yes & $6(15)$ \\
\hline \multicolumn{2}{|c|}{ Clinical/radiological diagnosis } \\
\hline Definite UIP & $26(63)$ \\
\hline Possible UIP & $15(37)$ \\
\hline \multicolumn{2}{|l|}{ Corticosteroids } \\
\hline No & $17(41)$ \\
\hline Yes & $24(59)$ \\
\hline \multicolumn{2}{|l|}{ Pirfenidone } \\
\hline No & $34(82.9)$ \\
\hline Yes & $7(17.1)$ \\
\hline \multicolumn{2}{|l|}{$\overline{N \text {-Acetylcysteine }}$} \\
\hline No & $36(88)$ \\
\hline Yes & $5(12)$ \\
\hline \multicolumn{2}{|c|}{ Time from diagnosis ${ }^{\mathrm{b}}$} \\
\hline $0-5$ months & $11(27)$ \\
\hline 6-11 months & $12(29)$ \\
\hline$>12$ months & $18(44)$ \\
\hline
\end{tabular}

Values are $n(\%) .{ }^{\text {a }}$ Mean age $70 \pm 8$ years. ${ }^{\mathrm{b}}$ Mean time from diagnosis $20 \pm 28$ months. UIP, usual interstitial pneumonia.

tion of the follow-up time was 7 months (range 2-16). A total of 6 deaths occurred during follow-up. The survival probability at 12 months was $79 \%$ (95\% CI: 58-91\%) (Fig. 2). 


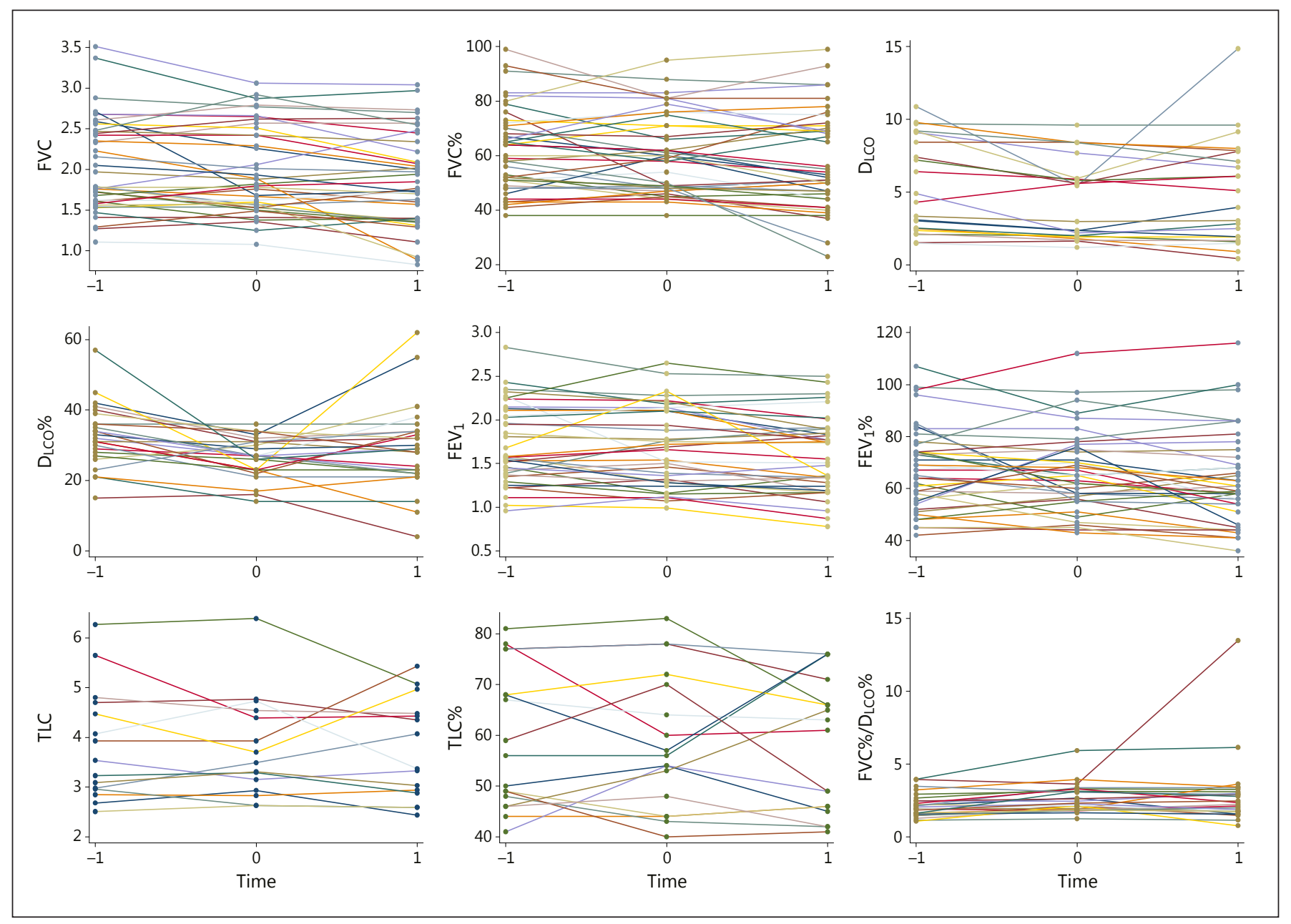

Fig. 1. Changes in the spirometry parameters evaluated at 6 months before starting treatment with nintedanib $\left(\mathrm{T}_{-1}\right)$, at the time of the first nintedanib intake $\left(\mathrm{T}_{0}\right)$ and at 6 months after the initiation of nintedanib therapy $\left(\mathrm{T}_{1}\right)$. FVC, forced vital capacity; $\mathrm{D}_{\mathrm{LCO}}$, diffusing capacity of the lung for carbon monoxide; $\mathrm{FEV}_{1}$, forced expiratory volume in 1 second; TLC, total lung capacity.
Fig. 2. Survival probability for patients followed up after 6 months of nintedanib treatment $(n=39)$.

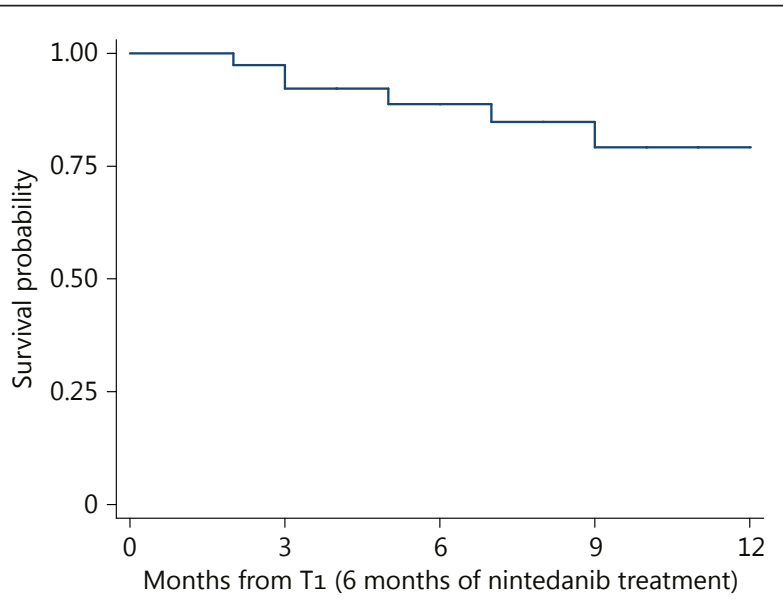

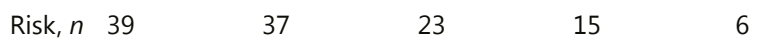


Table 2. Changes in lung function parameters at $\mathrm{T}_{-1}, \mathrm{~T}_{0}$, and $\mathrm{T}_{1}$

\begin{tabular}{|c|c|c|c|c|c|c|}
\hline Parameter & $N$ & Time & Mean (SD) & Changes $(95 \% \mathrm{CI})$ & $\begin{array}{l}\text { Difference } \\
\text { in changes }(\mathrm{SD})\end{array}$ & $p$ value \\
\hline FVC, L & $\begin{array}{l}39 \\
39 \\
39\end{array}$ & $\begin{array}{l}\mathrm{T}_{-1} \\
\mathrm{~T}_{0} \\
\mathrm{~T}_{1}\end{array}$ & $\begin{array}{l}2.05(0.58) \\
1.99(0.54) \\
1.87(0.58)\end{array}$ & $\begin{array}{l}- \\
-0.07(-0.15 ; 0.02) \\
-0.12(-0.20 ;-0.04)\end{array}$ & $\begin{array}{l}- \\
- \\
-0.06(0.36)\end{array}$ & 0.22 \\
\hline FVC $\%$ & $\begin{array}{l}41 \\
41 \\
41\end{array}$ & $\begin{array}{l}\mathrm{T}_{-1} \\
\mathrm{~T}_{0} \\
\mathrm{~T}_{1}\end{array}$ & $\begin{array}{l}61.83(15.25) \\
60.63(14.57) \\
58.00(17.77)\end{array}$ & $\begin{array}{l}- \\
-1.20(-3.78 ; 1.39) \\
-2.63(-5.21 ;-0.06)\end{array}$ & $-1.44(12.36)$ & 0.34 \\
\hline $\mathrm{D}_{\mathrm{LCO}}, \mathrm{mmol} / \mathrm{min} / \mathrm{kPa}$ & $\begin{array}{l}22 \\
22 \\
22\end{array}$ & $\begin{array}{l}\mathrm{T}_{-1} \\
\mathrm{~T}_{0} \\
\mathrm{~T}_{1}\end{array}$ & $\begin{array}{l}5.48(3.25) \\
4.50(2.77) \\
5.03(3.64)\end{array}$ & $\begin{array}{c}- \\
-0.98(-1.60 ;-0.37) \\
0.53(-0.47 ; 1.53)\end{array}$ & $1.51(3.46)$ & 0.03 \\
\hline $\mathrm{D}_{\mathrm{LCO}} \%$ & $\begin{array}{l}26 \\
26 \\
26\end{array}$ & $\begin{array}{l}\mathrm{T}_{-1} \\
\mathrm{~T}_{0} \\
\mathrm{~T}_{1}\end{array}$ & $\begin{array}{l}32.73(8.56) \\
26.54(5.70) \\
29.23(12.08)\end{array}$ & $\begin{array}{l}- \\
-6.19(-9.26 ;-3.12) \\
2.69(-1.54 ; 6.93)\end{array}$ & $8.88(15.30)$ & 0.004 \\
\hline $\mathrm{FEV}_{1} \%$ & $\begin{array}{l}39 \\
39 \\
39\end{array}$ & $\begin{array}{l}\mathrm{T}_{-1} \\
\mathrm{~T}_{0} \\
\mathrm{~T}_{1}\end{array}$ & $\begin{array}{l}67.62(16.02) \\
66.67(15.62) \\
63.62(17.66)\end{array}$ & $\begin{array}{l}- \\
-0.95(-4.43 ; 2.53) \\
-3.05(-5.64 ;-0.46)\end{array}$ & $-2.10(15.62)$ & 0.37 \\
\hline TLC, $\mathrm{L}$ & $\begin{array}{l}15 \\
15 \\
15\end{array}$ & $\begin{array}{l}\mathrm{T}_{-1} \\
\mathrm{~T}_{0} \\
\mathrm{~T}_{1}\end{array}$ & $\begin{array}{l}3.85(1.13) \\
3.78(1.03) \\
3.73(1.01)\end{array}$ & $\begin{array}{l}- \\
-0.07(-0.34 ; 0.20) \\
-0.05(-0.48 ; 0.38)\end{array}$ & $-0.02(1.07)$ & 1 \\
\hline TLC\% & $\begin{array}{l}17 \\
17 \\
17\end{array}$ & $\begin{array}{l}\mathrm{T}_{-1} \\
\mathrm{~T}_{0} \\
\mathrm{~T}_{1}\end{array}$ & $\begin{array}{l}59.06(13.73) \\
58.71(13.46) \\
57.65(13.16)\end{array}$ & $\begin{array}{l}- \\
-0.35(-4.34 ; 3.64) \\
-1.06(-6.60 ; 4.48)\end{array}$ & $-0.71(15.74)$ & 0.83 \\
\hline
\end{tabular}

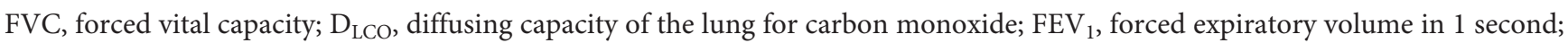
TLC, total lung capacity.

\section{Discussion}

To our knowledge, this is the first study that evaluated the effectiveness of nintedanib treatment in a patient population with severe IPF. Such a population has generally been excluded from randomized controlled trials. Our study has the typical pros and cons of real-life studies already discussed in previous papers $[14,16]$. It is at the same time a national multicenter retrospective analysis truly representative of the real situation of patients affected by a more severe form of IPF.

Our study population had the same characteristics as those in other studies. In particular, it was very similar to a patient series described in one of our previous investiga- tions on pirfenidone [14]. In our previous study, $75 \%$ of the enrolled patients were male $(83 \%$ in the present study), $79 \%$ had a history of smoking (73\% in the present study), and the mean age was 69 years (70 in this study). The only difference worth mentioning is the percentage of histological diagnoses. In our previous work, 25\% of the enrolled subjects had undergone lung biopsy versus only $15 \%$ in the present series. This is probably due to an even greater disease severity and the risks related to an invasive diagnostic procedure unlikely to significantly change disease management, as these patients would be denied antifibrotic therapies due to their functional conditions, until the introduction of the NPU program. Most patients with severe IPF enrolled in the present study had 
previously received low doses of steroids (59\%) as it is commonly the case in clinical practice. Only $8 \%$ had received $\mathrm{N}$-acetylcysteine and none had received azathioprine, which reflects the good adherence to the international and Italian treatment guidelines of the reference centers $[1,17]$. Only a few patients ( 7 subjects, $17 \%$ of the overall study population) had been formerly treated with pirfenidone, which was then discontinued because of side effects. Such a small number of individuals is unlikely to have substantially affected the trend in lung function before the beginning of nintedanib treatment. Previous treatment with low-dose steroids and subsequent tapering (not performed in all patients) should not have had an impact on the functional behavior of our population. The study population was too small to perform any analysis of these aspects. It was a homogeneous group of patients with a definitive or possible diagnosis of usual interstitial pneumonia.

The positive effect of nintedanib on the decline of absolute and $\mathrm{D}_{\mathrm{LCO}} \%$ predicted was not paralleled by a similar effect on either FVC or other parameters; however, differences in changes between post- and pretreatment for $\mathrm{D}_{\mathrm{LCO}} \%$ predicted and FVC\% predicted were positively and significantly correlated. This could be due to several reasons. A first hypothesis could be that the effect on $\mathrm{D}_{\mathrm{LCO}}$ foreshadows that on the FVC trend. This happens in other disorders such as lymphangioleiomyomatosis $[18,19]$ and could probably be identified by examining the data after a longer follow-up time. However, the severity of the patients' condition and their high risk of mortality led us to measure the trend before and after 6 months of treatment only, considering this period of time to be long enough to verify the level of exposure to the drug or to observe and record the trajectory of the disease. The effects on $\mathrm{D}_{\mathrm{LCO}}$ may be driven by some outliers with significant improvement, as seen in Figure 1; however, the data still remain significant without considering those. Finally, we preferred to keep all subjects in the data set using a method that is also robust for the presence of outliers. It should also be noted that only 26 out of $41 \mathrm{pa}$ tients were able to undergo the 3 pre-specified periodic determinations of $\mathrm{D}_{\mathrm{LCO}}$. In other words, we observed a positive trend in about half of our total sample, while approximately $40 \%$ of the patients were unable to tolerate the test at any time in the course of the study, indicating a more severe stage of disease. We hence believe that our data on nintedanib-induced change in $\mathrm{D}_{\mathrm{LCO}}$ should be interpreted with caution and evaluated more rigorously in future studies.
A further possible explanation is that the drug given to subjects so heavily compromised has sometimes been administered to cases too severely ill to produce a significant benefit. The high mortality at 12 months (21\%) is counterevidence of this. A severity subgroup analysis of patients enrolled in the INPULSIS trials has suggested that the drug effect is identical in the different subsets of patients stratified based on FVC value and GAP index [20, $21]$. This was not confirmed in our group of severely compromised patients. Reassuringly, however, we observed that patients with a more favorable trend in $\mathrm{D}_{\mathrm{LCO}} \%$ variation were also those with a more favorable trend in FVC\%. It is possible that a larger patient population followed for a longer time could have uncovered positive results also with respect to FVC. It is equally likely that nintedanib had an effect on pulmonary hypertension generally associated with the advanced stages of IPF [22] as it happens with other tyrosine kinases inhibitors in subjects with pulmonary arterial hypertension [23]. However, this is only an entirely speculative hypothesis since no data support it (echocardiographic data provided by the participating centers were unfortunately too limited to allow a precise estimation; yet, no significant variation in FVC\%/ $\mathrm{D}_{\mathrm{LCO}} \%$ was observed). A review article by Meltzer and Noble [24] suggests that $D_{\text {LCO }}$ strongly correlates with pulmonary hypertension and that there is a negative correlation between them. In a randomized placebo-controlled trial on imatinib in IPF over 96 weeks, $D_{\text {LCO }}$ was a secondary end point that at all different time points of observation did not change in the experimental arm compared to the control group [25]. Our study is therefore the first to report a possible improvement in lung diffusion capacity following treatment with an antifibrotic medication specific to IPF.

These data are important because they highlight that 1 of the 2 antifibrotic drugs currently available for the treatment of IPF may also be effective in the more advanced stages of the disease. The mechanism of action that influences the variations of absolute and $\mathrm{D}_{\mathrm{LCO}} \%$ in this series still needs to be explored, but the trend gives an important and positive signal. The lung diffusion capacity is indeed considered, together with FVC, as one of the most important prognostic factors for IPF [26-31]. This result is even more significant given that it was recorded in a real-life study that more closely reflects the real complexity of sick patients than the selected populations in clinical trials do.

Our work has many limitations. It is a retrospective study, and the number of patients is limited, although the cohort studied here summarizes the defining features of typical patients well. Due to the characteristics of the sub- 
jects and the severity of their disease, it was not possible to collect data about other important parameters that would otherwise have enabled a more detailed interpretation of our findings. These include the 6-min walk test (only a few patients performed it and an even smaller proportion of them had serial tests due to the severity of their condition) and an echocardiographic study for the detection of a possible associated pulmonary hypertension. $\mathrm{Pa}$ tients who had to discontinue therapy for any reasons including side effects and toxicities during the first 6 months of treatment were not included in our study, and therefore, it was not possible to analyze these data. Finally, our results might also be interpreted as a negative study due to the absence of effect of nintedanib on the trend of FVC; however, for the reasons discussed above, this is not our interpretation. The difference in trend between absolute and $\mathrm{D}_{\mathrm{LCO}} \%$ values on the one hand and FVC on the other hand needs to be further investigated in prospective studies involving a larger population of patients. Despite these limitations, which are common to studies of this kind, we believe that the final message of this work is interesting. It in fact opens up venues for the evaluation of nintedanib even in the most severely sick patients who are today orphans of any treatment, have a very poor prognosis, and await therapeutic answers beyond palliation. In addition, therapies able to slow down the course of the disease, even in its most advanced stages, could be a bridge to lung transplantation. In conclusion, this nation- wide multicenter experience in patients with severe IPF shows that nintedanib slows down the rate of decline of absolute and \% predicted $\mathrm{D}_{\mathrm{LCO}}$ but does not have a significant impact on the decline of FVC or other lung function parameters.

\section{Financial Disclosure and Conflicts of Interest}

S.H. reports personal fees from Roche, grants and personal fees from InterMune, and grants and personal fees from Boehringer Ingelheim outside the submitted work. A.C. reports personal fees from Boerhinger Ingelheim and Roche outside the submitted work. V.P. reports personal fees from Boehringer Ingelheim and Roche outside the submitted work. D.L. reports personal fees from Boehringer Ingelheim outside the submitted work. F.L. reports personal fees from Boehringer Ingelheim and grants and personal fees from Roche outside the submitted work. P.S. reports personal fees and nonfinancial support from Roche, personal fees and nonfinancial support from Boehringer Ingelheim, personal fees from Santhera Pharmaceuticals, personal fees from Galapagos, personal fees from InterMune, and personal fees from Novartis outside the submitted work. C.V. reports grants and personal fees from Roche and Boehringer Ingelheim outside the submitted work. M.P. reports personal fees from Roche and Boehringer Ingelheim outside the submitted work. S.C. reports personal fees from Roche, Boehringer Ingelheim, and Chiesi Farmaceutici outside the submitted work. M.P.F.B reports personal fees from Boehringer Ingelheim outside the submitted work. S.T. reports personal fees from Boehringer Ingelheim and Roche outside the submitted work. The other authors had nothing to disclose.

\section{References}

1 Raghu G, Collard HR, Egan JJ, Martinez FJ, Behr J, Brown KK, et al: An official ATS/ERS/ JRS/ALAT statement: idiopathic pulmonary fibrosis: evidence-based guidelines for diagnosis and management. Am J Respir Crit Care Med 2011;183:788-824.

2 Harari S, Madotto F, Caminati A, Conti S, Cesana GC: Epidemiology of idiopathic pulmonary fibrosis in Northern Italy. PLoS One 2016;11:e0147072.

-3 Noble PW, Albera C, Bradford WZ, Costabel U, Glassberg MK, Kardatzke D, et al: Pirfenidone in patients with idiopathic pulmonary fibrosis (CAPACITY): two randomized trials. Lancet 2011;377:1760-1769.

-4 King TE Jr, Bradford WZ, Castro-Bernardini S, Fagan EA, Glaspole I, Glassberg MK, et al: A phase 3 trial of Pirfenidone in patients with idiopathic pulmonary fibrosis. N Engl J Med 2014;370:2083-2092.

5 Richeldi L, Costabel U, Selman M, Kim DS, Hansell DM, Nicholson AG, et al: Efficacy of a tyrosine kinase inhibitor in idiopathic pul- monary fibrosis. N Engl J Med 2011;365: 1079-1087.

-6 Richeldi L, du Bois RM, Raghu G, Azuma A, Brown KK, Costabel U, et al: Efficacy and safety of nintedanib in idiopathic pulmonary fibrosis. N Engl J Med 2014;370:2071-2082.

-7 Okuda R, Hagiwara E, Baba T, Kitamura H, Kato T, Oqura T: Safety and efficacy of pirfenidone in idiopathic pulmonary fibrosis in clinical practice. Respir Med 2013;107:1431-1437.

8 Oltmanns U, Khan N, Palmowski K, Träger A, Wenz H, Heussel CP, et al: Pirfenidone in idiopathic pulmonary fibrosis: real-life experience from a German tertiary referral center for interstitial lung diseases. Respiration 2014;88:199-207.

-9 Chaudhuri N, Duck A, Frank R, Holme J, Leonard C: Real word experiences: pirfenidone is well tolerated in patients with idiopathic pulmonary fibrosis. Respir Med 2014; 108:224-226.

10 Salih GN, Shaker SB, Madsen HD, Bendatrup E: Pirfenidone treatment in idiopathic pul- monary fibrosis: nationwide Danish results. Eur Clin Respir J 2016;3:32608.

-11 Sköld CM, Janson C, Elf AK, Fiaschi M, Wiklund K, Persson HL: A retrospective chart review of pirfenidone-treated patients in Sweden: the REPRIS study. Eur Clin Respir J 2016; 3:32035.

12 Hughes G, Toellner H, Morris H, Leonard C, Chaudhuri N: Real world esperiences: pirfenidone and nintedanib are effective and well tolerated treatments for idiopathic pulmonary fibrosis. J Clin Med 2016;5:E78.

13 Bonella F, Kreuter M, Hagmeyer L, Neurohr C, Keller C, Kohlhaeufl MJ, et al: Insights from the German compassionate use program of nintedanib for the treatment of idiopathic pulmonary fibrosis. Respiration 2016; 92:98-106.

14 Harari S, Caminati A, Albera C, Vancheri C, Poletti V, Pesci A, et al: Efficacy of pirfenidone for idiopathic pulmonary fibrosis; an Italian real life study. Respir Med 2015;109: 904-913.
Nintedanib in Severe Idiopathic

Pulmonary Fibrosis 
15 Wuyts WA, Kolb M, Stowasser S, Stansen W, Huggins JT, Raghu G: First data on efficacy and safety of nintedanib in patients with idiopathic pulmonary fibrosis and forced vital capacity of $\leq 50 \%$ of predicted value. Lung 2016; 194:739-743.

16 Harari S, Caminati A: Idiopathic pulmonary fibrosis: from clinical trials to real-life experiences. Eur Respir Rev 2015;24:420-427.

17 Raghu G, Rochwerg B, Zhang Y, Cuoello Garcia CA, Azuma A, Behr J, et al: An official ATS/ERS/JRS/ALAT Clinical practice guideline: treatment of idiopathic pulmonary fibrosis. An update of the 2011 clinical practice guideline. Am J Respir Crit Care Med 2015; 192:e3-e19.

18 Chu SC, Horiba K, Usuki J, Avila NA, Chen CC, Travis WD, et al: Comprehensive evaluation of 35 patients with lymphangioleiomyomatosis. Chest 1999;115:1041-1052.

19 Taveira-DaSilva AM, Moss J: Clinical features, epidemiology, and therapy of lymphangioleiomyomatosis. Clin Epidemiol 2015;7: 249-257.
20 Costabel U, Inoue Y, Richeldi L, Collard HR, Tschoepe I, Stowasser S, et al: Efficacy of nintedanib in idiopathic pulmonary fibrosis across prespecified subgroups in INPULSIS. Am J Respir Crit Care Med 2016;193:178185.

21 Ryerson CJ, Kolb M, Richeldi L, Lee J, Kimura T, Stowasser S, Poletti V: Effect of baseline GAP index stage on decline in lung function with nintedanib in patients with idiopathic pulmonary fibrosis (IPF). Am J Respir Crit Care Med 2016;193:A2691.

22 Caminati A, Cassandro R, Harari S: Pulmonary hypertension in chronic interstitial lung diseases. Eur Respir Rev 2013;22:292-301.

23 Frost AE, Barst RJ, Hoeper MM, Chang HJ, Frantz RP, Fukumoto Y, et al: Long-term safety and efficacy of imatinib in pulmonary arterial hypertension. J Heart Lung Transplant 2015;34:1366-1375.

24 Meltzer EB, Noble P: Idiopathic pulmonary fibrosis. Orphanet J Rare Dis 2008;3:8.

25 Daniels CE, Lasky JA, Limper AH, Mieras K, Gabor E, Schroeder DR: Imatinib-IPF Study Investigators. Imatinib treatment for idiopathic pulmonary fibrosis: randomized placebo-controlled trial results. Am J Respir Crit Care Med 2010;181:604-610.

26 Kolb M, Collard HR: Staging of idiopathic pulmonary fibrosis: past, present and future. Eur Respir Rev 2014;23:220-224.
7 Flaherty KR, Mumford JA, Murray S, Kazerooni EA, Gross BH, Colby TV, et al: Prognostic implications of physiologic and radiographic changes in idiopathic interstitial pneumonia. Am J Respir Crit Care Med 2003; 168:543-548.

28 Collard HR, King TE Jr, Bartelson BB, Vourlekis JS, Schwarz MI, Brown KK: Changes in clinical and physiologic variables predict survival in idiopathic pulmonary fibrosis. Am J Respir Crit Care Med 2003;168:538-542.

29 Latsi PI, du Bois RM, Nicholson AG, Colby TV, Bisirtzoglou D, Nikolakopoulou A, et al: Fibrotic idiopathic pneumonia: the prognostic value of longitudinal functional trends. Am J Respir Crit Care Med 2003;168:531537.

30 Egan J, Martinez F, Wells A, Williams T: Lung function estimates in idiopathic pulmonary fibrosis: the potential for a simple classification. Thorax 2005;60:270-273.

31 Caminati A, Harari S: IPF: new insight in diagnosis and prognosis. Respir Med 2010; 104:S2-S10. 